\title{
Influence of Bison bonasus on flora and vegetation change in Krasnikovsky forestry of "Orlovskoe Polesie" national park
}

\author{
L.L. Kiseleva ${ }^{1}$, Zh.G. Silaeva ${ }^{2}, N . N$. Chaadaeva $^{1}$, E.A. Parakhina ${ }^{3, *}$ \\ ${ }^{1}$ Orel State University named after I.S. Turgenev, Department of Plant Botany, Physiology and \\ Biochemistry, Orel, Russia \\ ${ }^{2}$ Orel State Agrarian University named after N.V. Parakhina, Department of landscape architecture, \\ Orel, Russia \\ ${ }^{3}$ Peoples Friendship University of Russia (RUDN University), Faculty of Ecology, 6 Miklukho- \\ Maklaya St, Moscow, 117198, Russian Federation
}

\begin{abstract}
The purpose of the study is to reveal the influence of European bison (Bison bonasus) on flora and vegetation change in Krasnikovsky forestry of "Orlovskoe Polesie" national park. In August-September of 2019, floristic and geobotanical studies of flora and vegetation were carried out at self-feeding stations, in the locations of salt licks, as well as in the bisons' passage points in Krasnikovsky forestry of "Orlovskoe Polesie" national park. There were identified 142 species of vascular plants of 9 phytocenotic formations according to G. Zozulin's classification: nemoral, birch forest, helobious grass, alder, boreal-willow, boreal forest, pine forest, meadow and anthropogenic. The number of phytocenotic groups and the percentage of species in each of them varied. A direct relationship was established between the time of self-feeding stations formation and the participation of non-forest species in the corresponding phytocenoses: the earlier self-feeding station was formed, the higher the participation percentage in the coen of non-forest species. When assessing geobotanical descriptions according to the Ramensky's pasture digression ecological scale it was revealed that the greatest digression degree is observed in the locations of self-feeding stations: from a moderate influence of grazing (semi-pasture stage, 5 points) to a weak influence of grazing (hay stage, 4.5 points). In places adjacent to feeding self-feeding stations, or bisons' passages, a weak influence of grazing was noted, a haying stage (3.7-4.0 points). In the places solonetzic soil locations, the influence of grazing does not affect ( 2 points) or there is a weak influence of grazing, haying stage (3-4 points).
\end{abstract}

\section{Introduction}

The National Park "Orlovskoe Polesie" is in the northwestern part of Orel region on the territory of Znamensky and Khotynetsky districts in the subzone of coniferous-deciduous forests. Its area is 77.745 hectares. One of the main activities of the park, which has been

\footnotetext{
* Corresponding author: parakhina-ea@,rudn.ru
} 
under way since 1996, is the formation of a stable free-ranging bisons' (Bison bonasus) population (Bison bonasus) according to the Program for the Bisons' Conservation in Russia. Currently, the bison population numbers 490 individuals [1].

Bison are living fossils that have miraculously survived to this day. This is one of the few species that managed to return to the wild after almost complete extermination. The species is included in the "Red List" of the International Union for Conservation of Nature (IUCN) - it has the status of vulnerable, in Appendix III of the Bern Convention, the Red Data Books of the Russian Federation, Belarus, Lithuania, Poland, Ukraine, etc. In Europe, a significant part of natural ecosystems in which once bison lived, mastered by man. A significant role in the return of bison to natural ecosystems is assigned to Russia, which has large areas for potential habitation of the animal in its natural environment.

In 2018, studies were carried out on the effect of bison reintroduction on the national park earthworm complexes [2], but detailed studies of the population effect on the flora and vegetation of the park have not been carried out yet, so the chosen topic is very relevant.

\section{Research methods}

Purpose of the study: to reveal the influence of European bison (Bison bonasus) on flora and vegetation change in of Krasnikovsky forestry of "Orlovskoe Polesie" national park. To solve this goal, the following tasks were set: 1) to identify the composition of vascular plants flora: at self-feeding stations; in the locations of salt licks; in the bisons' passage points; 2) to determine the pasture digression of vegetation degree on self-feeding stations, in the locations of salt licks and in the bisons' passage points.

When conducting field research, the route method and the method of geobotanical descriptions were used [3]. With the route method, all encountered species of vascular plants were recorded in the field journal at self-feeding stations, in the locations of salt licks, and in the bisons' passage points. To determine the coordinates of self-feeding stations, salt licks and bisons' passage points, the GPS-navigator "Garmin III +" (accuracy up to 0.001') was used. During geobotanical studies in the researched phytocenoses, standard sample areas with a size of $100 \mathrm{~m} 2$ were laid. The projective cover of the species was assessed using the combined Braun-Blanquet scale [4]: " $r$ " - the species is very rare, 1-4 individuals per site; "+" - the projective cover of the species individuals is less than $1 \%$; "1" - from $1 \%$ to $5 \%$; "2" - from $6 \%$ to $25 \%$; "3" - from $26 \%$ to $50 \%$; "4" - from $51 \%$ to $75 \%$; "5" - more than $75 \%$. The vascular plants identification was carried out using various literary sources [5-9]. When processing geobotanical descriptions according to the Ramensky's ecological scales [10], the EcoScaleWin computer program was used [11].

\section{Results and discussion}

In August-September of 2019, floristic and geobotanical studies of flora and vegetation were carried out at self-feeding stations, in the locations of salt licks, as well as in the bisons' passage points in Krasnikovsky forestry of "Orlovskoe Polesie" national park. The location of the research sites is shown in Fig. 1. 


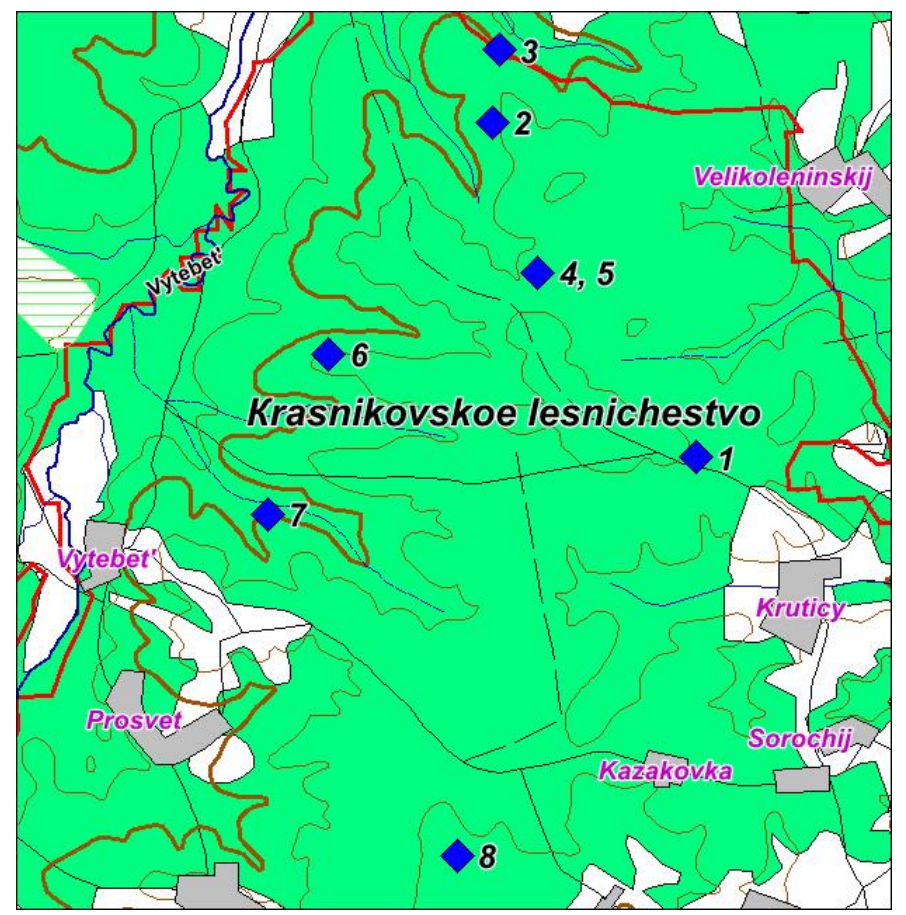

Fig. 1. Location of research sites for flora and vegetation at self-feeding stations, in the locations of salt licks, as well as in the bisons' passage points in Krasnikovsky forestry of "Orlovskoe Polesie" national park:

1 - Self-feeding station, 84 sq.; 2 - Bolshevik urochishche. 16 sq. Solonets; 3 - Bisons' passage point, 10 sq.; 4, 5 - Old and new salt lick, 42 sq.; 6 - Self-feeding station, 37 sq.; 7 - Self-feeding station, Gavryushina Polyana, 62 sq.; 8 - Self-feeding station, Levkina Polyana, 136 sq.

There were identified 142 species of vascular plants of 9 phytocenotic formations according to G. Zozulin's classification [12]: nemoral, birch forest, helobious grass, alder, boreal-willow, boreal forest, pine forest, meadow and anthropogenic. The number of phytocenotic groups and the percentage of species in each of them varied. Comparison of the percentage participation of different phytocenotic accompanying plants species in geobotanical descriptions made it possible to reveal the following patterns:

A direct relationship was established between the time of self-feeding stations formation and the participation of non-forest species in the corresponding phytocenoses: the earlier selffeeding station was formed, the higher the participation percentage in the coen of non-forest species. So, on the site, formed in 2012, about $64 \%$ of non-forest species $(50 \%$ anthropogenic and $14 \%$ meadow $)$ were found directly at the feeding area and $35 \%(12 \%$ anthropogenic and $23 \%$ meadow) - on the fringe of the forest; on the site formed in 2013, the share of non-forest species was 59\% (27\% - anthropogenic and 32\% - meadow); on the site formed in 2014, the share of non-forest species was 56\% (24\% - anthropogenic and 32\% - meadow), the site of 2017 formation included $27 \%$ of non-forest species (17\% - anthropogenic and $10 \%$ meadow).

In a phytocenosis with salt-licks, established on the site of a former agricultural cooperative that existed here in the 60s. of XX century, the share of non-forest species was $21 \%$ (anthropogenic $-13 \%$, meadow $-8 \%$ ); on the territory of the salt licks, organized in $2012,18 \%$ of non-forest species (3\% - anthropogenic and 15\% - meadow); and in the place where the new salt-lick was formed (August 2019), no non-forest species (meadow and anthropogenic) were found. 
In places adjacent to self-feeding stations or the bisons' passage points, the percentage of non-forest species in phytocenoses does not exceed $10 \%$.

In addition to floristic composition of forest phytocenoses change, bisons, like many other animals, during their life, are able to influence the vegetation and transform it. In this regard, the assessment of pasture digression on the territories of self-feeding stations, the locations of salt licks and the bisons' passage points becomes relevant.

Assessment of geobotanical descriptions according to L. Ramensky's pasture digression ecological scale (1956) showed the following results:

In the locations of self-feeding stations (descriptions 1, 10, 12, 9, 2, Fig. 2), the assessment of the habitat on the scale of pasture digression is: from a moderate influence of grazing (semi-grazing stage, 5 points) to a weak influence of grazing (haying stage, 4,5 points).

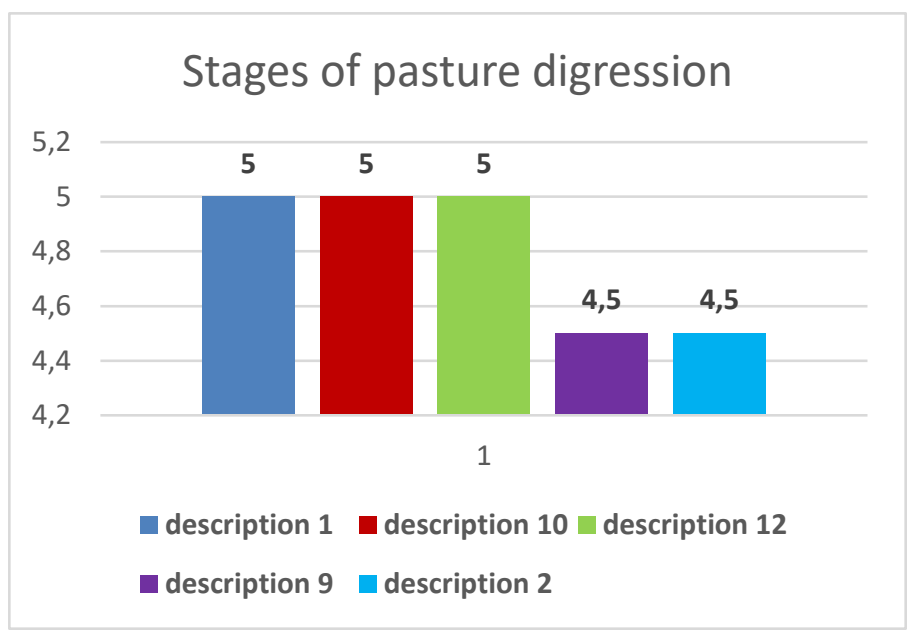

Fig. 2. Stages of pasture digression in the locations of self-feeding stations

In the places where salt licks are located, the assessment of the habitat on the scale of pasture digression is the following: the influence of grazing does not affect ( 2 points, description 8) or weak influence of grazing, haying stage (3-4 points, descriptions 5 and 6 ) (Fig. 3).

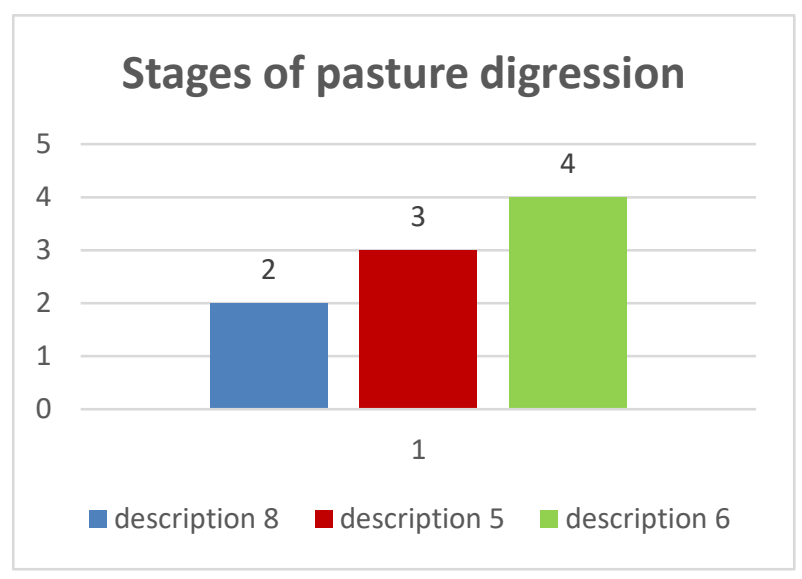

Fig. 3. Stages of pasture digression in the locations of salt licks

In places adjacent to self-feeding stations, or bison passages, a weak influence of grazing was noted, the haying stage (3.7-4.0 points) (descriptions 3,4,7,11) (Fig. 4). 


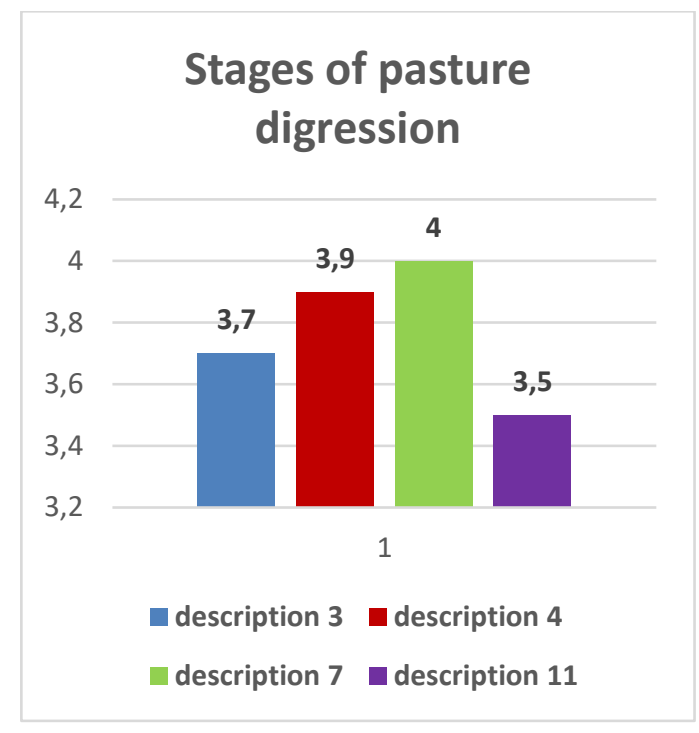

Fig. 4. Stages of pasture digression in areas adjacent to self-feeding stations

During the study, cases of oppression (trampling) and eating of plants, their ground parts, and sometimes pulling them out were noted. So, for example, in an aspen-birch forest located $20 \mathrm{~m}$ far from the self-feeding station, in places of bison bed (description 4), aspen bark scuffs were noted.

On the territory of a salt lick in a maple-aspen-spruce forest in 10 sq. of Krasnikovsky forestry in in the bisons' passage points, spruce roots with removed outer bark were found, as well as eating creeping buttercup, ashweed, louseberry, sycamore maple, field maple, wild leek.

In a maple-aspen-birch forest (the location of the old salt lick) 42 sq. observed the bare roots of the field maple, and noted the complete trampling of the grass-shrub layer

\section{Conclusions}

The analysis of floristic composition changes of phytocenoses because of the influence of bison allowed to deduce the following regularities:

A direct relationship was established between the time of self-feeding stations formation and the participation of non-forest species in the corresponding phytocenoses: the earlier selffeeding station was formed, the higher the participation percentage in the coen of non-forest species. So, on the site, formed in 2012 , about $64 \%$ of non-forest species $(50 \%$ anthropogenic and $14 \%$ meadow) were found directly at the feeding area and $35 \%(12 \%$ anthropogenic and $23 \%$ meadow) - on the fringe of the forest; on the site formed in 2013, the share of non-forest species was 59\% (27\% - anthropogenic and 32\% - meadow); on the site formed in 2014, the share of non-forest species was 56\% (24\% - anthropogenic and 32\% - meadow), the site of 2017 formation included $27 \%$ of non-forest species (17\% - anthropogenic and 10\% meadow).

The number of anthropogenic and meadow species in forest phytocenoses in the places of salt licks for European bison also depends on the year of its establishment: in a phytocenosis with salt-licks, established on the site of a former agricultural cooperative that existed here in the $60 \mathrm{~s}$. of XX century, the share of non-forest species was $21 \%$ (anthropogenic - 13\%, meadow - 8\%); on the territory of the salt licks, organized in 2012, $18 \%$ of non-forest species ( $3 \%$ - anthropogenic and $15 \%$ - meadow); and in the place where 
the new salt-lick was formed (August 2019), no non-forest species (meadow and anthropogenic) were found.

In places adjacent to self-feeding stations or the bisons' passage points, the percentage of non-forest species in phytocenoses does not exceed $10 \%$.

Assessment of geobotanical descriptions according to L. Ramensky's pasture digression ecological scale (1956) showed the following results:

- In the locations of self-feeding stations the assessment of the habitat on the scale of pasture digression is the following: from a moderate influence of grazing (semi-grazing stage, 5 points) to a weak influence of grazing (haying stage, 4,5 points).

- In the places where salt licks are located, the assessment of the habitat on the scale of pasture digression is the following: the influence of grazing does not affect or weak influence of grazing, haying stage (3-4 points).

- In places adjacent to self-feeding stations, or bison passages, a weak influence of grazing was noted, the haying stage (3.7-4.0 points).

In addition to oppression and trampling of plants, other signs of a direct effect on plants were noted: eating plants (for example, creeping buttercup, common runny, wild leek, etc.), their ground parts, bark (common spruce, aspen, mountain ash, field maple, etc.), and sometimes pulling them out.

\section{References}

1. Orel Polesie National Park official website https://orlpolesie.ru/ [23.02.2021].

2. A.P. Geraskina, L.L. Kiseleva, A.P. Karpachev, M.N. Abadonova, Russian J. of Ecosystem Ecology, 3(4) (2018)

3. A.A. Yunatov, Field geobotany, 9-36 (Publishing House of the Academy of Sciences of the USSR (Leningrad Department), Leningrad, 1964)

4. J. Braun-Blanquet, Pflanzensoziologie (1964).

5. I.A. Gubanov, K.V. Kiseleva, V.S. Novikov, V.N. Tihomirov, Illustrated Plant Identifier of Central Russia, v.1 (Moscow, 2002)

6. I.A. Gubanov, K.V. Kiseleva, V.S. Novikov, V.N. Tihomirov, Illustrated Plant Identifier of Central Russia, v.2 (Moscow, 2003)

7. I.A. Gubanov, K.V. Kiseleva, V.S. Novikov, V.N. Tihomirov, Illustrated Plant Identifier of Central Russia, v.2 (Moscow 2004)

8. V.N. Tikhomirov V.N., T.O. Yanitskaya, G.A. Pronkina. Zontichnye Srednej Rossii. Opredelitel' po vegetativnym priznakam (Argus, Moscow, 1996)

9. P.F. Mayevsky. Flora of the middle belt of the European part of Russia (KMK Scientific Press, Moscow, 2014)

10. L.G. Ramensky, I.A. Tsatsenkin, O.N. Chizhikov, N.A. Antipov, Ecological assessment of forage lands by vegetation cover, (Selkhozgiz, Moscow, 1956)

11. E.V. Zubkova, L.G. Khanina, T.I. Grokhlina, Yu.A. Dorogova, Computer processing of geobotanical descriptions by ecological scales using EcoScaleWin software, (Mar. State University, Pushchino State University, Yoshkar-Ola, 2008)

12. G.M. Zozulin, Botanicheskij zhurnal, 58, 1081-1092 (1973) 